\title{
PENGEMBANGAN MODEL PEMBELAJARAN PROJECT BASED LEARNING PADA MATA KULIAH PENYUNTINGAN BAHASA INDONESIA BERBASIS TEKNOLOGI INFORMASI DAN KOMUNIKASI
}

\author{
Reni Oktaviani ${ }^{1}$, N. Lia Marliana ${ }^{2}$ \\ 1,2Program Studi Pendidikan Bahasa dan Sastra Indonesia, Universitas Negeri Jakarta \\ Email: ${ }^{1}$ renioktaviani@unj.ac.id, ${ }^{2}$ nliamarliana@unj.ac.id
}

\begin{abstract}
This study aims to develop a project-based learning model in the Information and Communication Technology (ICT)-based Indonesian Editing course. This study uses research and development. The stages in this research are: first, analyzing student needs in an ICT-based learning model that is relevant to the Indonesian Language Editing course. Second, integrating the ICT-based learning model with RPS in the Indonesian Language Editing course. Third, explain the process of developing an ICT-based project-based learning model in the Indonesian Language Editing course. The results of data processing for the development of a project-based learning model in the ICT-based Indonesian language editing course at the pre-test average were 68.67, while the post-test had an average score of 85.09. This result increased by 16.67. Based on this, the development of a project-based learning learning model in the ICT-based Indonesian Language Editing course for level IV students of the Indonesian Language and Literature Education Study Program obtained effective results to be applied in learning.
\end{abstract}

Keywords: Project-Based Learning Model, Indonesian Language Editing, ICT

\begin{abstract}
Abstrak
Penelitian ini bertujuan untuk mengembangkan model pembelajaran project based learning pada mata kuliah Penyuntingan Bahasa Indonesia berbasis Teknologi Informasi dan Komunikasi (TIK). Penelitian ini menggunakan penelitian dan pengembangan (research and development). Tahapan dalam penelitian ini, yaitu: pertama, melakukan analisis kebutuhan mahasiswa dalam model pembelajaran berbasis TIK yang relevan pada mata kuliah Penyuntingan Bahasa Indonesia. Kedua, mengintegrasi model pembelajaran berbasis TIK dengan RPS pada mata kuliah Penyuntingan Bahasa Indonesia. Ketiga, menjelaskan proses pengembangan model pembelajaran project based learning berbasis TIK pada mata kuliah Penyuntingan Bahasa Indonesia. Hasil pengolahan data pengembangan model pembelajaran project based learning pada mata kuliah penyuntingan bahasa indonesia berbasis TIK pada prates rata-ratanya 68,67 , sedangkan post test diperoleh nilai rata-rata 85,09. Hasil tersebut naik sebesar 16,67. Berdasarkan hal tersebut, pengembangan model pembelajaran project based learning pada mata kuliah Penyuntingan Bahasa Indonesia berbasis TIK pada mahasiswa tingkat IV Prodi Pendidikan Bahasa dan Sastra Indonesia memperoleh hasil yang efektif untuk diterapkan dalam pembelajaran.
\end{abstract}

Kata kunci: Model Pembelajaran Project Based Learning, Penyuntingan Bahasa Indonesia, TIK

\section{PENDAHULUAN}

Bahasa sangat penting dalam menjalankan aktivitas sehari-hari. Hampir semua kegiatan menggunakan bahasa untuk komunikasi antarindividu maupun kelompok. Bahasa dapat berupa lisan maupun tulisan. Melalui tulisan, seseorang dapat mengemukakan ide dan menyampaikan tujuan yang ingin dicapai.

Keterampilan berbahasa terdiri atas keterampilan reseptif dan produktif (Arwansyah \& Urip Muhayat Wiji Wahyudi, 2019). Untuk menghasilkan tulisan yang berkualitas diperlukan keterampilan berbahasa yang memadai, yaitu keterampilan menyimak, membaca, berbicara, dan menulis. Menulis adalah kemampuan menggunakan bahasa untuk berkomunikasi dengan menggunakan bahasa tulis (Putra et al., 2019). Menulis juga merupakan suatu kegiatan produktif yang dilakukan seseorang untuk menuangkan ide secara terstruktur melalui tulisan agar informasi atau pesan tersampaikan dan dipahami oleh pembaca. Menurut (Smith, 2020), 
writing is rather like recycling paper, you give the texts you have read another life through the way you reshape them. Keterampilan menulis merupakan salah satu keterampilan berbahasa yang bertujuan untuk menuangkan ide melalui rangkaian kata yang memiliki makna.

Keterampilan menulis sangat diperlukan dalam mata kuliah Penyuntingan Bahasa Indonesia sebab apa yang dituliskan akan disajikan kepada masyarakat atau pembaca. Keterampilan menulis tidak didapatkan secara instan dan hanya dapat dikuasai dengan rajin berlatih. Keterampilan menulis diperlukan dalam proses pembelajaran khususnya pada mata kuliah Penyuntingan Bahasa Indonesia.

Penyuntingan merupakan mata kuliah pilihan yang diampu oleh mahasiswa tingkat IV Prodi Pendidikan Bahasa dan Sastra Indonesia (PBSI), Universitas Negeri Jakarta (UNJ). Penyuntingan sangat diperlukan dalam sebuah naskah karena tulisan yang baik dan benar membuat informasi yang terkandung di dalamnya tersampaikan secara jelas kepada pembaca. Penyuntingan merupakan proses memeriksa kembali tulisan sebelum dipublikasikan. Capaian Pembelajaran Mata Kuliah (CPMK) ini untuk menguasai konsep dasar penyuntingan, baik di media massa, lembaga bahasa, maupun di penerbitan buku. Selain itu, CPMK lain yang tidak kalah penting yaitu mampu mempraktikkan keterampilan menyunting naskah, baik di media massa, lembaga bahasa, maupun di penerbitan buku.

Salah satu keterampilan menulis yang diajarkan pada mata kuliah Penyuntingan Bahasa Indonesia yaitu menyunting. Dalam mata kuliah tersebut, mahasiswa dituntut untuk dapat membuat tulisan atau teks yang sesuai dengan PUEBI (Pedoman Umum Ejaan Bahasa Indonesia) dan menyuntingnya sehingga menjadi tulisan atau teks yang layak untuk disampaikan. Penggunaan bahasanya pun berbeda. Bahasa yang digunakan di media massa biasa disebut sebagai bahasa jurnalistik (Arta et al., 2018). Mahasiswa dapat membuat tulisan atau teks berkualitas dan menyunting dengan baik dan benar jika menguasai kosakata, PUEBI, diksi, dan lainnya.

Penerapan pembelajaran mata kuliah Penyuntingan beberapa minggu dilakukan di kelas tetapi sejak Covid-19 menyerang semua pembelajaran menggunakan tatap maya. Hal tersebut dilakukan untuk mencegah penularan Covid-19 menjangkit pembelajar, baik di sekolah maupun perguruan tinggi (Kurniawan, 2021). Pembelajaran daring dilakukan oleh hampir seluruh institusi pendidikan dengan pembelajaran jarak jauh yang membutuhkan alat komunikasi seperti gawai, tablet, laptop, computer, dan koneksi internet (Yani \& Irma, 2021). Mata kuliah ini juga memerlukan alat komunikasi tersebut untuk melaksanakan penyuntingan.

Berdasarkan prates yang dilakukan pada pertemuan pertama perkuliahan bahwa pengetahuan awal mahasiswa belum cukup memadai. Hal ini menunjukkan bahwa pembelajaran menulis perlu ditingkatkan. Kosakata mahasiswa yang masih terbatas, perlu menambah pengetahuan dalam menyunting sehingga hasil tulisan atau teks dapat maksimal. Penyuntingan akan terasa sulit jika mahasiswa belum memiliki keterampilan menulis. Keengganan mahasiswa untuk menulis dan menyunting disebabkan ketidaktahuan bagaimana melakukan kedua hal tersebut dengan baik dan benar.

Di balik tuntutan di atas, ditemui kendala terkait dengan proses pembelajaran pada mata kuliah Penyuntingan. Mahasiswa belum mempunyai keterampilan yang memadai dalam penyuntingan. Keterampilan menyunting mahasiswa dapat ditingkatkan melalui berbagai cara. Salah satunya dengan pengembangan model pembelajaran project based learning pada mata kuliah Penyuntingan Bahasa Indonesia berbasis TIK.

Pembelajaran berbasis proyek atau dikenal dengan project based learning merupakan suatu model pembelajaran yang berfokus pada kreativitas berpikir, pemecahan masalah, dan interaksi antara peserta didik dengan teman sebayanya untuk menciptakan dan menggunakan pengetahuan baru (Wajdi, 2017). Selain itu, model pembelajaran ini dapat juga mengembangkan kreativitas secara kolaboratif dalam memecahkan masalah. Pembelajaran berbasis proyek dilibatkan mahasiswa untuk menghasilkan produk karya yang bernilai dengan menciptakan pembelajaran efektif dan menyenangkan (Annafi \& Agustina, 2018; Nuryanti et al., 2016)

Jika dicermati, penggunaan model pembelajaran yang sesuai dan berinovasi dapat mencapai tujuan pembelajaran yang diharapkan. Kelas merupakan komunitas yang mempunyai karakteristik yang berbeda-beda, maka peneliti memilih model pembelajaran sesuai dengan kondisi yang dihadapi. Salah satu cara yang dapat 
diterapkan dosen dalam kelas dengan memanfaatkan TIK yang sesuai dengan kebutuhan pada mata kuliah Penyuntingan Bahasa Indonesia. Seiring dengan perkembangan zaman, permutakhiran TIK mengalami perubahan hampir setiap detik.

Information Communication Technology (ICT) atau Teknologi Informasi dan Komunikasi (TIK) merupakan teknologi masa kini yang meliputi perangkat keras dan lunak berfungsi untuk menyampaikan informasi atau pesan dalam hitungan detik serta dapat dijumpai pada media elektronik seperti radio, televisi, komputer, maupun telepon (Umar \& Jamiat, 2011). Saat ini pemanfaatan TIK diperlukan dalam proses pembelajaran. Semakin mutakhir teknologi, berbagai media, alat, dan bahan ikut berkembang pesat (Syarifudin, 2020).

TIK diyakini memberikan kontribusi positif dalam meningkatkan kualitas pembelajaran, baik proses maupun hasil (Koesnandar, 2020). Kreativitas tenaga pendidik perlu dikembangkan melalui model pembelajaran yang disesuaikan dengan perkembangan zaman.

Berdasarkan uraian di atas, dalam penelitian ini akan membahas pengembangan model pembelajaran project based learning pada mata kuliah Penyuntingan Bahasa Indonesia berbasis Teknologi Informasi dan Komunikasi.

\section{METODOLOGI PENELITIAN}

Model pembelajaran selalu berkembang untuk meningkatkan kualitas pendidikan dan pembelajaran (Diyah Nurul Qotimah, 2020). Penelitian ini menggunakan pengembangan model pembelajaran project based learning pada mata kuliah Penyuntingan Bahasa Indonesia berbasis TIK. Research and Development adalah metode penelitian yang digunakan untuk menghasilkan suatu produk tertentu dan menguji keefektifan produk tersebut (Lestari et al., 2019). Penelitian dan pengembangan juga merupakan salah satu metode penelitian untuk mengembangan atau memvalidasi produk yang digunakan dalam pendidikan dan pembelajaran. (Amil et al., 2020). Penelitian ini dilaksanakan sejak April sampai November 2020. Tempat pelaksanaan penelitian ini di UNJ. Penelitian ini juga menggunakan skala Likert (Muslim et al., 2019).

Hal ini dilakukan dalam penelitian ini yaitu pertama, analisis kebutuhan mahasiswa dalam model pembelajaran berbasis TIK pada mata kuliah Penyuntingan Bahasa Indonesia.
Kedua, mengintegrasi model pembelajaran berbasis TIK dengan RPS pada mata kuliah Penyuntingan Bahasa Indonesia. Ketiga, menjelaskan proses pengembangan model pembelajaran project based learning berbasis TIK pada mata kuliah Penyuntingan Bahasa Indonesia. Teknik analisis data berupa teknik analisis isi. Selain itu, dilakukan perbandingan saat tahap awal, tengah, dan akhir dalam penelitian ini dengan mengembangkan model pembelajaran project based learning pada mata kuliah Penyuntingan Bahasa Indonesia berbasis TIK.

\section{HASIL DAN PEMBAHASAN}

Awal penelitian ini dilakukan secara tatap muka tetapi pada Maret 2020 pandemi Covid-19 melanda Indonesia sehingga penelitian ini dilanjutkan secara daring (tatap maya) untuk meminimalisasi penularan akibat wabah yang sedang terjadi. Pertemuan pertama diadakan prates dengan menjawab soal sebanyak 50 soal yang diberikan oleh dosen. Selain itu, diberikan pula kuesioner analisis kebutuhan yang berkaitan dengan mata kuliah Penyuntingan. Pengolahan data dapat dilakukan setelah memverifikasi kuesioner analisis kebutuhan yang dibagikan kepada 43 mahasiswa.

Untuk mengetahui kemampuan mahasiswa dalam menyunting, dilakukan prates sebelum dilakukan pengembangan model pembelajaran project based learning pada mata kuliah Penyuntingan Bahasa Indonesia berbasis TIK. Hasil tes tersebut menunjukkan nilai terendah yang diperoleh mahasiswa sebesar 30 dan nilai tertingginya 97, dengan nilai rata-rata 68,67 dan berkriteria kurang. Jika dibuat dalam kelas interval nilai terendahnya 30, sedangkan nilai tertinggi 97. Distribusi frekuensi dari nilai Penyuntingan Bahasa Indonesia sebelum dilakukan pengembangan model pembelajaran sebagai berikut.

Tabel 1. Distribusi Frekuensi Skor Sebelum Pengembangan Model Pembelajaran

\begin{tabular}{|c|c|c|c|}
\hline No. & Kelas Interval & Frekuensi & Persentase \\
\hline 1. & $30-39$ & 2 & $5 \%$ \\
\hline 2. & $40-49$ & 7 & $16 \%$ \\
\hline 3. & $50-59$ & 1 & $2 \%$ \\
\hline 4. & $60-69$ & 11 & $26 \%$ \\
\hline 5. & $70-79$ & 10 & $23 \%$ \\
\hline 6. & $80-89$ & 10 & $23 \%$ \\
\hline 7. & $90-99$ & 2 & $5 \%$ \\
\hline \multirow{2}{*}{\multicolumn{2}{|c|}{$\begin{array}{l}\text { Jumlah } \\
\text { Pengembanga }\end{array}$}} & 43 & $100 \%$ \\
\hline & & model & pembelajar \\
\hline
\end{tabular}


Penyuntingan Bahasa Indonesia berbasis TIK mengacu pada hasil kuesioner analisis kebutuhan, kuesioner refleksi, dan hasil suntingan. Data tersebut dikembangkan menjadi model pembelajaran yang sesuai dengan kebutuhan dan kondisi mahasiswa pada mata kuliah Penyuntingan Bahasa Indonesia. Evaluasi berbentuk tes yang dipergunakan dosen untuk menguji pemahaman mahasiswa. Selanjutnya mengulang materi secara singkat dan membuat simpulan pelajaran. Sebelum akhir pembelajaran, dosen memberi tugas kelompok berupa proyek menyunting berdasarkan pengamatan yang dimiliki mahasiswa.

Analisis kebutuhan diujikan pada responden untuk mengetahui hal-hal yang diperlukan dalam model pembelajaran project based learning pada mata kuliah Penyuntingan Bahasa Indonesia berbasis TIK. Kuesioner analisis kebutuhan berjumlah 10 butir. Hasil identifikasi analisis kebutuhan dengan responden mahasiswa menunjukkan bahwa (1) kegiatan menyunting naskah sudah pernah dilakukan sebelumnya, (2) memanfaatkan fitur-fitur yang ada di komputer untuk menyunting, (3) senang menyunting naskah dari media massa mengenai kasus kesalahan berbahasa, (4) menggunakan KBBI daring untuk memudahkan dalam menyunting, (5) mengalami kendala yang disebabkan kekurangcermatan dan kekurangtelitian saat menyunting, belum menguasai materi kebahasaan, dan kaidah berbahasa dari Badan Bahasa yang tidak konsisten, (6) memberikan alternatif solusi dalam mengatasi kendala dalam menyunting dengan cara meminta bantuan mahasiswa lain untuk saling mengecek tugas kuliah atau naskah untuk menghindari kekurangcermatan atau kekurangtelitian sendiri, menggunakan gawai jika komputer bermasalah, dan membaca sumber rujukan lain, serta (7) mengerjakan penyuntingan secara berkelompok lebih efektif dibandingkan secara individu.

Tahap pengembangan model pembelajaran project based learning pada mata kuliah Penyuntingan Bahasa Indonesia berbasis TIK dilakukan melalui materi, metode, proses, dan desain pembelajaran yaitu 1) materi. Materi yang diberikan kepada mahasiswa mengenai naskah berita yang ada sekitar dan berhubungan dengan kesalahan berbahasa untuk disunting. Materi tersebut sesuai dengan Rencana Pembelajaran Semester (RPS). Materi dalam pembelajaran yang disunting mengenai kasus- kasus kesalahan berbahasa yang ada di sekitar yang diberikan kepada mahasiswa agar dapat menyuntingnya dengan benar. 2) metode. Hal yang perlu diperhatikan dalam model pembelajaran project based learning pada mata kuliah Penyuntingan Bahasa Indonesia berbasis TIK berupa pemahaman menyunting naskah serta penguasaan Pedoman Umum Ejaan Bahasa Indonesia (PUEBI), Tata Bahasa, dan Kamus Besar Bahasa Indonesia, 3) proses. Proses pembelajaran mata kuliah penyuntingan yaitu berdasarkan langkah-langkah model pembelajaran project based learning berbasis TIK yang sesuai dengan kebutuhan pembelajaran, 4) desain. Desain pembelajaran menggunakan model pembelajaran project based learning pada mata kuliah Penyuntingan Bahasa Indonesia berbasis TIK sesuai analisis kebutuhan yang disebarkan kepada mahasiswa.

Berdasarkan hasil diskusi dengan dosen mata kuliah Penyuntingan, diperoleh hasil mengenai desain model pengembangan, pengolahan data, dan penilaian pada model pembelajaran ini relatif tidak ada masalah sebab sebagian besar mahasiswa pernah melakukan penyuntingan. Hasil penerapan model pembelajaran project based learning berbasis TIK ini diprediksi mampu meningkatkan keterampilan menyunting mahasiswa tingkat IV Prodi Pendidikan Bahasa dan Sastra UNJ.

Proses model pembelajaran project based learning pada mata kuliah Penyuntingan Bahasa Indonesia berbasis TIK sebagai berikut.

1. Kegiatan inti dalam tahap penentuan proyek, mahasiswa mengembangkan pemikirannya dalam menyunting naskah yang berkaitan dengan kesalahan berbahasa.

Produk yang dikembangkan berupa materi dengan menerapkan model pembelajaran project based learning pada mata kuliah Penyuntingan Bahasa Indonesia berbasis TIK dengan memanfaatkan fitur yang ada dalam Google Classroom untuk menyunting yang dilakukan mahasiswa Prodi Pendidikan Bahasa dan Sastra Indonesia UNJ tingkat IV. Pada awal perancangan langkah penyelesaian proyek, mahasiswa dibimbing dosen memahami tentang penyuntingan. Pembagian tugas dalam menyunting antara mahasiswa sebab model pembelajaran project based learning berbasis TIK dilakukan secara berkelompok.

Tahap pelaksanaan, mahasiswa memetakan kendala dalam penyuntingan 
beserta solusinya. Tahap akhir, tindak lanjut apabila proyek itu terselesaikan. Pada tahap evaluasi proses dan hasil proyek, dosen dan mahasiswa melakukan refleksi terhadap naskah yang telah disunting beserta hasilnya. Mahasiswa dapat mengemukakan kendala dalam penyuntingan. Dosen memberikan masukan yang berhubungan dengan kualitas suntingan yang telah dikumpulkan.

2. Kegiatan penutup. Naskah berita disunting berdasarkan kesalahan berbahasa yang ada di sekitar mahasiswa. Dosen melatih mahasiswa untuk peka terhadap penulisan yang disajikan sehingga meminimalisasi kesalahan berbahasa yang terjadi di sekitarnya.

Proses model pembelajaran project based learning berbasis TIK dilakukan oleh peneliti sekaligus dosen mata kuliah Penyuntingan. Dosen pengampu utama mata kuliah penyuntingan selalu mendampingi proses pembelajaran dan memberikan penilaian. Sebagian mahasiswa antusias melakukan proses penyuntingan tetapi masih ada yang kurang memahami proses yang dijelaskan oleh dosen. Pertemuan selanjutnya, banyak mahasiswa yang mulai memahami dan menguasai proses penyuntingan naskah yang diberikan oleh dosen. Materi yang diberikan oleh dosen berkaitan dengan kesalahan berbahasa yang ada di sekitar dan sesuai dengan RPS.

Aspek penilaian yang dilakukan oleh mahasiswa sehingga naskah yang disunting menggunakan penulisan yang baik dan benar meliputi kemampuan menyunting mahasiswa tingkat IV Prodi Pendidikan Bahasa dan Sastra Indonesia UNJ diketahui dari hasil penyuntingan pertama. Data tersebut dianalisis berdasarkan aspek penyuntingan meliputi kosakata, ejaan, huruf kapital, tanda baca, dan sebagainya. Kalimat efektif juga menjadi salah satu aspek penyuntingan yang dinilai.

\section{Tabel 2. Nilai Prates dan Post Test}

\begin{tabular}{|c|c|c|}
\hline & Prates & Post Test \\
\hline Nilai Rata-rata & 68,67 & 85,09 \\
\hline
\end{tabular}

Adapun hasil pengolahan data, diketahui adanya pengembangan model pembelajaran project based learning pada mata kuliah penyuntingan bahasa indonesia berbasis TIK. Hal ini dapat dilihat dari perhitungan post test diperoleh nilai rata-rata 85,09 , sedangkan rata- rata pada prates rata-ratanya 68,67 . Hasil tersebut naik sebesar 16,67.

Hasil post test keterampilan menyunting yang dilakukan mahasiswa, nilai terendah 73 , sedangkan nilai tertinggi 91. Nilai rata-rata sebesar 85,09 dengan kriteria baik. Jadi dapat disimpulkan bahwa keterampilan menyunting mahasiswa Prodi Pendidikan Bahasa dan Sastra Indonesia UNJ tingkat IV sesudah pengembangan model pembelajaran berada pada kategori baik.

Hasil penelitian di atas menunjukkan dosen menerapkan model pembelajaran project based learning berbasis TIK yang telah dikembangkan sangat menarik dalam proses pembelajaran menyunting. Hasil penelitian yang sangat signifikan ditunjukkan sebanyak 39 mahasiswa (91\%) memahami tentang proses penyuntingan dengan menggunakan model pembelajaran project based learning berbasis TIK dan hasilnya sangat memuaskan.

Jadi dapat disimpulkan bahwa proses penyuntingan dengan menerapkan pengembangan model pembelajaran project based learning berbasis TIK sangat menarik mahasiswa sehingga memudahkan dalam menyunting. Dalam menerapkan pengembangan model pembelajaran project based learning berbasis TIK, dosen tidak mengalami kendala dan kemampuan menyunting mahasiswa meningkat. Mahasiswa antusias dalam menyunting dan mencari kesalahan berbahasa yang ada di sekitar. Materi yang diberikan oleh dosen sesuai dengan tujuan pembelajaran yang ada dalam RPS.

Sebagian besar mahasiswa memahami proses penyuntingan dan menyunting naskah, walaupun ada beberapa siswa yang masih mengalami kesulitan. Distribusi frekuensi dari nilai penyuntingan setelah dilakukan pengembangan model pembelajaran sebagai berikut.

Tabel 3. Distribusi Frekuensi Skor Setelah Pengembangan Model Pembelajaran

\begin{tabular}{|c|c|c|c|}
\hline No. & Kelas Interval & Frekuensi & Persentase \\
\hline 1 & $70-79$ & 2 & $5 \%$ \\
\hline 2 & $80-89$ & 37 & $86 \%$ \\
\hline 3 & $90-99$ & 4 & $9 \%$ \\
\hline \multicolumn{2}{|c|}{ Jumlah } & 43 & $100 \%$ \\
\hline
\end{tabular}

Jadi dapat disimpulkan bahwa hasil post test keterampilan menyunting mahasiswa Prodi Pendidikan Bahasa dan Sastra Indonesia UNJ tingkat IV setelah pengembangan model pembelajaran berada pada kategori baik. 
Pengembangan model pembelajaran ini diserahkan kepada dosen ahli untuk dilakukan validasi sehingga dapat diketahui apa saja kelemahan dan kekuatannya. Berdasarkan hasil validasi didapatkan tingkat kelayakan produk yang dihasilkan. Ada tiga aspek yang dinilai dalam proses validasi, yaitu kelayakan materi, penyajian, dan ejaan. Berikut hasil dari tiap aspek yang dinilai.

\section{Aspek Kelayakan Materi}

Berdasarkan penghitungan validasi aspek materi nilai rata-rata validasi adalah 4,25 dengan kategori baik. Hasil validasi aspek kelayakan materi dipaparkan sebagai berikut.

Tabel 4. Kelayakan Materi

\begin{tabular}{|c|c|c|c|c|c|c|c|}
\hline \multirow{2}{*}{ No. } & \multirow{2}{*}{ Aspek } & \multirow{2}{*}{$\begin{array}{c}\text { Aspek yang } \\
\text { Dinilai }\end{array}$} & \multicolumn{5}{|c|}{ Skor } \\
\hline & & & 1 & 2 & 3 & 4 & 5 \\
\hline \multirow[t]{3}{*}{1} & \multirow{3}{*}{$\begin{array}{l}\text { Kesesuaian } \\
\text { materi } \\
\text { dengan RPS }\end{array}$} & Kelengkapan materi & & & & $\mathrm{V}$ & \\
\hline & & Kesesuaian materi & & & & & $\mathrm{V}$ \\
\hline & & Kedalaman materi & & & & $\mathrm{V}$ & \\
\hline \multirow[t]{3}{*}{2} & \multirow{3}{*}{$\begin{array}{l}\text { Keakuratan } \\
\text { materi }\end{array}$} & Keakuratan konsep & & & & & V \\
\hline & & $\begin{array}{l}\text { Keakuratan contoh } \\
\text { dan kasus }\end{array}$ & & & & $\mathrm{V}$ & \\
\hline & & $\begin{array}{l}\text { Keakuratan dalam } \\
\text { menyunting }\end{array}$ & & & & V & \\
\hline \multicolumn{3}{|c|}{ Jumlah } & & \multicolumn{4}{|c|}{26} \\
\hline \multicolumn{3}{|c|}{ Rata-Rata } & & \multicolumn{4}{|c|}{4,33} \\
\hline \multicolumn{3}{|c|}{ Kategori } & & \multicolumn{4}{|c|}{ Baik } \\
\hline
\end{tabular}

\section{Aspek Kelayakan Penyajian Materi}

Berdasarkan penghitungan validasi aspek materi nilai rata-rata validasi adalah 4,28 dengan kategori baik. Hasil validasi aspek kelayakan materi dipaparkan sebagai berikut.

Tabel 5. Kelayakan Penyajian Materi

\begin{tabular}{|c|c|c|c|c|c|c|c|}
\hline \multirow{2}{*}{ No. } & \multirow{2}{*}{ Aspek } & \multirow{2}{*}{$\begin{array}{c}\text { Aspek yang } \\
\text { Dinilai }\end{array}$} & \multicolumn{5}{|c|}{ Skor } \\
\hline & & & 1 & 2 & 3 & 4 & 5 \\
\hline \multirow[t]{2}{*}{1} & \multirow[t]{2}{*}{$\begin{array}{l}\text { Konsistensi } \\
\text { dan } \\
\text { keruntunan } \\
\text { penyajian }\end{array}$} & $\begin{array}{l}\text { Konsistensi } \\
\text { sistematika sajian } \\
\text { dalam } \\
\text { pembelajaran }\end{array}$ & & & & $\mathrm{V}$ & \\
\hline & & $\begin{array}{l}\text { Keruntunan } \\
\text { konsep }\end{array}$ & & & & $\mathrm{V}$ & \\
\hline \multirow[t]{3}{*}{2} & \multirow{3}{*}{$\begin{array}{l}\text { Penyusunan } \\
\text { naskah } \\
\text { suntingan } \\
\text { yang sesuai } \\
\text { dengan } \\
\text { kegiatan } \\
\text { pembelajaran }\end{array}$} & Pemberian prates & & & & & V \\
\hline & & $\begin{array}{l}\text { Contoh-contoh } \\
\text { penyuntingan }\end{array}$ & & & & V & \\
\hline & & $\begin{array}{l}\text { Pemberian post } \\
\text { test }\end{array}$ & & & & & $\mathrm{V}$ \\
\hline \multirow[t]{2}{*}{3} & \multirow[t]{2}{*}{$\begin{array}{l}\text { Penguatan } \\
\text { materi } \\
\text { pembelajaran }\end{array}$} & \begin{tabular}{|l|} 
Refleksi \\
penguasaan \\
materi
\end{tabular} & & & & V & \\
\hline & & Simpulan materi & & & & V & \\
\hline \multicolumn{3}{|c|}{ Jumlah } & \multicolumn{5}{|c|}{30} \\
\hline \multicolumn{3}{|c|}{ Rata-Rata } & \multicolumn{5}{|c|}{4,28} \\
\hline \multicolumn{3}{|c|}{ Kategori } & \multicolumn{5}{|c|}{ Baik } \\
\hline
\end{tabular}

\section{Aspek Kelayakan Ejaan}

Berdasarkan penghitungan validasi aspek materi nilai rata-rata validasi adalah 4,28 dengan kategori baik. Hasil validasi aspek kelayakan materi dipaparkan sebagai berikut.

Tabel 6. Kelayakan Ejaan

\begin{tabular}{|c|c|c|c|c|c|c|c|}
\hline \multirow{2}{*}{ No. } & \multirow{2}{*}{ Aspek } & \multirow{2}{*}{$\begin{array}{c}\text { Aspek yang } \\
\text { Dinilai }\end{array}$} & \multicolumn{5}{|c|}{ Skor } \\
\hline & & & 1 & 2 & 3 & 4 & 5 \\
\hline \multirow[t]{7}{*}{1} & \multirow{7}{*}{$\begin{array}{l}\text { Struktur dan } \\
\text { keefektifan } \\
\text { kalimat }\end{array}$} & Struktur kalimat & & & & $\mathrm{V}$ & \\
\hline & & Kalimat efektif & & & & V & \\
\hline & & Tata bahasa & & & & $\mathrm{V}$ & \\
\hline & & Kosakata & & & & & V \\
\hline & & Istilah & & & & & $\mathrm{V}$ \\
\hline & & Tanda baca & & & & V & \\
\hline & & $\begin{array}{l}\text { Pengunaan huruf } \\
\text { kapital }\end{array}$ & & & & V & \\
\hline \multicolumn{3}{|c|}{ Jumlah } & \multicolumn{5}{|c|}{30} \\
\hline \multicolumn{3}{|c|}{ Rata-Rata } & \multicolumn{5}{|c|}{4,28} \\
\hline \multicolumn{3}{|c|}{ Kategori } & \multicolumn{5}{|c|}{ Baik } \\
\hline
\end{tabular}

Berdasarkan hasil validasi dosen ahli, nilai rata-rata aspek kelayakan materi sebesar 4,33 dengan kategori baik. Aspek kelayakan penyajian materi sebesar 4,28 dengan kategori baik, sedangkan aspek kelayakan ejaan nilai ratarata validasi 4,28 dengan kategori baik. Jadi dapat disimpulkan model pembelajaran project based learning pada mata kuliah Penyuntingan Bahasa Indonesia berbasis TIK dapat meningkatkan keterampilan menyunting mahasiswa tingkat IV Prodi Pendidikan Bahasa dan Sastra Indonesia UNJ.

Kegiatan menyunting harus dibiasakan oleh mahasiswa agar pengetahuan awal tentang penyuntingan diperdalam saat berlangsungnya proses pembelajaran. Pembelajaran dosen selalu mengajukan pertanyaan dan meminta mahasiswa untuk memberikan contoh yang relevan dengan materi yang sedang dibahas. Keefektifan pembelajaran sebelum pengembangan model pembelajaran project based learning pada mata kuliah Penyuntingan Bahasa Indonesia berbasis TIK menunjukkan bahwa nilai rata-rata sebelumnya 68,67 berkategori cukup. Hasil pengembangan model pembelajaran project based learning pada mata kuliah Penyuntingan Bahasa Indonesia berbasis TIK setelah diterapkan sebesar 85,09.

Pada pertemuan terakhir, mahasiswa diberikan kuesioner refleksi mata kuliah penyuntingan dengan menggunakan model pembelajaran project based learning berbasis TIK setelah pembelajaran. Hal ini bertujuan agar mahasiswa memberikan tanggapan terhadap model pembelajaran project based learning berbasis TIK yang digunakan. Selain itu, untuk 
melihat sejauh mana kesesuaian model pembelajaran tersebut dalam mata kuliah penyuntingan berbasis TIK.

Refleksi dengan responden mahasiswa dalam pengembangan model pembelajaran project based learning pada mata kuliah Penyuntingan Bahasa Indonesia berbasis TIK menunjukkan bahwa (1) mahasiswa lebih mudah dan senang menyunting dengan memanfaatkan fitur-fitur yang ada di komputer daripada manual dengan tanda-tanda koreksi naskah, (2) mahasiswa lebih suka menyunting kesalahan berbahasa dari sekeliling mereka dibandingkan kasus-kasus kesalahan berbahasa di media massa, (3) kasus-kasus kesalahan di media massa daring lebih banyak ditemukan daripada di media cetak, (4) sumber belajar yang dipergunakan berupa KBBI edisi $\mathrm{V}$ daring dan PUEBI, (5) kendala yang sering dialami mahasiswa yaitu belum menguasai materi Penyuntingan dan kekurangcermatan dan kekurangtelitian saat menyunting, (6) solusi yang dilakukan mahasiswa dengan cara membaca sumber rujukan lain, menggunakan gawai jika komputer bermasalah, dan bekerja bersama mahasiswa lain secara berkelompok untuk saling mengecek hasil suntingan untuk menghindari kekurangcermatan atau kekurangtelitian sendiri, (7) mahasiswa lebih efektif bekerja secara berkelompok dengan menggunakan perangkat komputer dan memanfaatkan TIK saat melaksanakan pembelajaran berbasis kasus-kasus secara kontekstual kesalahan berbahasa di media massa atau media lain.

Pengembangan model pembelajaran project based learning pada mata kuliah Penyuntingan Bahasa Indonesia berbasis TIK pada mahasiswa Prodi Pendidikan Bahasa dan Sastra Indonesia memperoleh hasil yang efektif untuk diterapkan dalam pembelajaran.

\section{SIMPULAN DAN SARAN}

Berdasarkan hasil penelitian, dapat disimpulkan bahwa pengembangan model pembelajaran project based learning berbasis TIK dapat diterapkan dan mengalami keberhasilan melalui pelaksanaan prates dan post test dalam mata kuliah penyuntingan di Prodi Pendidikan Bahasa dan Sastra Indonesia UNJ. Langkah-langkah implementasi pengembangan model pembelajaran project based learning pada mata kuliah Penyuntingan Bahasa Indonesia berbasis TIK yaitu: 1) penentuan pertanyaan mendasar; 2) mendesain perencanaan proyek; 3) menyusun jadwal; dan 4) memonitor mahasiswa dan kemajuan proyek. Setelah pengembangan model pembelajaran project based learning pada mata kuliah Penyuntingan Bahasa Indonesia berbasis TIK diimplementasikan, langkah berikutnya evaluasi dengan memberikan post test.

Adapun hasil pengembangan model pembelajaran project based learning pada mata kuliah penyuntingan bahasa indonesia berbasis TIK pada prates rata-ratanya 68,67 , sedangkan post test diperoleh nilai rata-rata 85,09 . Hasil tersebut naik sebesar 16,67. Pengembangan model pembelajaran project based learning pada mata kuliah Penyuntingan Bahasa Indonesia berbasis TIK pada mahasiswa tingkat IV Prodi Pendidikan Bahasa dan Sastra Indonesia memperoleh hasil yang efektif untuk diterapkan dalam pembelajaran.

Saran penelitian ini, diharapkan dosen memilih model pembelajaran yang sesuai dengan materi yang diajarkan. Model pembelajaran project based learning cocok diterapkan pada mata kuliah Penyuntingan Bahasa Indonesia berbasis TIK. Model pembelajaran ini dikembangkan berdasarkan kebutuhan lapangan dan dapat direvisi sesuai dengan kebutuhan.

\section{REFERENSI}

Amil, A. J., Setyawan, A., \& Dellia, P. (2020). Pengembangan Media Pembelajaran Keterampilan Membaca Berbasis Android Pokok Pembahasan Legenda Desa-Desa Di Madura Pada Pembelajaran Bahasa Indonesia Kelas Vii Smp Negeri Se-Kabupaten Bangkalan. Jurnal Pendidikan Bahasa Dan Sastra Indonesia Metalingua, 5(2), 83-86.

https://doi.org/10.21107/metalingua.v5i2. 8628

Annafi, N., \& Agustina, S. (2018). Pengembangan Model Pembelajaran Project Based Learning (PBL) Berbasis Kearifan Lokal untuk Mempersiapkan Calon Pendidik yang Berbudaya Development of Learning Model Project Based Learning ( PBL ) Based on Local Wisdom to Prepare Cultured Educator Candid. 9(1), 1-10.

Arta, G., Putra, S., Artawan, G., \& Wirahyuni, K. (2018). Analisis Gaya Bahasa pada Berita Seni Budaya dalam Surat Kabar 
Bali Post Edisi Mei 2018. 4743(May), 28-36.

Arwansyah, Y. B., \& Urip Muhayat Wiji Wahyudi. (2019). Peningkatkan Kompetensi Literasi Antiradikalisme Melalui Penulisan Cerita Rakyat dengan Aplikasi Baboo. Jurnal Pendidikan Bahasa Dan Sastra Indonesia Metalingua, 4(2), 77-82.

Diyah Nurul Qotimah, H. N. (2020). Pengaruh Model Pembelajaran Mind Mapping Terhadap Kemampuan Menentukan Struktur Teks Negosiasi. Jurnal Pendidikan Bahasa Dan Sastra Indonesia Metalingua, 5(2), 77-82.

Koesnandar, A. (2020). Pengembangan Model Pembelajaran Inovatif Berbasis Teknologi Informasi dan Komunikasi ( TIK ) Sesuai The Development of ICTBased Innovative Learning Models of K13. 08(01), 33-61.

Kurniawan, P. Y. (2021). Pengembangan Bahan Ajar Interaktif dengan Menggunakan Aplikasi Lectora Inspire untuk Mahasiswa Pendidikan Bahasa dan Sastra Indonesia. Jurnal Pendidikan Bahasa Dan Sastra Indonesia Metalingua, 6(1), 37-42.

Lestari, N. M. C. P., Sutama, I. M., \& Utama, I. D. G. B. (2019). Pengembangan Media Pembelajaran Visual Bagi Pebelajar Bipa Pemula Di Undiksha. Jurnal Pendidikan Bahasa Dan Sastra Indonesia Undiksha, $8(1)$, 86-95. https://doi.org/10.23887/jjpbs.v8i1.20535

Muslim, U., Al, N., \& Medan, W. (2019). Pengembangan Model Pembelajaran Berbasis Proyek Dalam Menulis Teks Eksplanasi di Kelas XI SMA. 5(1), 74-85. https://doi.org/10.24235/ileal.v5i1.5033

Nuryanti, M., Arfiyanti, R., \& Muliawati, H. (2016). PENGEMBANGAN MODEL PEMBELAJARAN. 2013, 53-66.

Putra, I. N. T., Sutresna, I. B., \& Darmayanti, I. A. M. (2019). Pemanfaatan Teknik Kata
Kunci Untuk Meningkatkan Kemampuan Menulis Teks Eksposisi Siswa Kelas X Mipa 5 Sma N 1 Payangan I. Jurnal Pendidikan Bahasa Dan Sastra Indonesia Undiksha, 8(2), 235-247. https://doi.org/10.23887/jjpbs.v8i2.20617

Smith, H. (2020). The Writing Experiment: Strategies for Innovative Creative Writing. Allen \& Unwin.

Syarifudin, A. S. (2020). Implementasi Pembelajaran Daring Untuk Meningkatkan Mutu Pendidikan Sebagai Dampak Diterapkannya Social Distancing. Jurnal Pendidikan Bahasa Dan Sastra Indonesia Metalingua, 5(1), 31-34.

https://doi.org/10.21107/metalingua.v5i1. 7072

Umar, I. N., \& Jamiat, N. (2011). Pola penyelidikan ICT dalam pendidikan guru di Malaysia: analisis prosiding teknologi pendidikan Malaysia. The Asia Pacific Journal of Educators and Education (Formerly Known as Journal of Educators and Education), 26(1), 1-14.

Wajdi, F. (2017). Implementasi Project Based Learning (Pbl) Dan Penilaian Autentik Dalam Pembelajaran Drama Indonesia. Jurnal Pendidikan Bahasa Dan Sastra, $17(1)$, 86. https://doi.org/10.17509/bs_jpbsp.v17i1. 6960

Yani, T. A., \& Irma, C. N. (2021). Keterlibatan Orang Tua Dalam Pembelajaran Bahasa Indonesia Di Masa Pandemi Pada Siswa Sd Negeri 02 Pengarasan Kecamatan Bantarkawung. Jurnal Pendidikan Bahasa Dan Sastra Indonesia Metalingua, 6(1), 11-18. https://doi.org/10.21107/metalingua.v6i1. 9084 